\title{
Policies of Women Empowerment in Decision Making Positions: The Case of Egypt 2014- 2020
}

\author{
Salwa Al Said Farrag \\ Associate professor, Head of the Political Science Department, Suez Canal University
}

\begin{abstract}
This study seeks to assess the policies of empowering Egyptian women in decision-making positions as well as identifying the challenges that limit the chances of women in taking over leadership positions. Additionally, a number of secondary goals were investigated such as; defining the concept of empowerment and leadership with a focus on their types and dimensions, identifying the characteristics and skills of women leaders, understanding the aspects of women empowerment in decision-making positions as well as monitoring and evaluating the existing stance of women in leading positions. The study showed that the leadership empowerment of women is progressing at a fast and advanced pace, which indicates that the empowerment of women is amongst the key goals of the 2030 vision and recommends additional procedures to ensure consistency of such policies to support sustainable societal development.
\end{abstract}

Keywords: Women - Empowerment - Decision Making - Leadership positions - development

DOI: $10.7176 / \mathrm{JLPG} / 112-12$

Publication date:August $31^{\text {st }} 2021$

\section{Introduction: -}

1. Background and Orientation of the Study

An in-depth focus and concern to women and feminine issues is considered a cornerstone of the local and global trends. Issues related to women economic, political and social empowerment are key features of these trends. Sine that gender equality and women empowerment are not a mere part of human rights, but rather steering wheels and engines of economic prosperity and development progress, the development process in any community needs the participation of all its members, men and women together. Development will never be sustained without the active participation of women. For further illustration, growth is questioned as long as little progress is made in raising the capacities of women academically and culturally.

Therefore, the participation of women in the public and political spheres; as well as, in the decision-making processes is a proof for cultural progression and scientific development. This, by extension, puts women in an equal position to men.

In addition, two key foundation are crucial to the development and advancement of communities: gender equality and women empowerment. Both pillars are vital to ensure the full promotion and protection of human rights that is in accordance with relevant international conventions.

Women-related issues have received a significant attention from international conventions and conferences. Statutory laws were highly concerned to issue laws that ensure women's rights in freedom, education and work. In addition, laws have called for the necessity of expanding women's participation levels, competing on leadership positions, contributing to the decision-making process, etc.

Egyptian women are seen as key players in the development sphere. Nonetheless, their contribution is highly dependent on the rights they receive and the opportunities they are given to practice their full participation as active members of the society paving the way to modernization and reform.

It is, however, important to highlight that women are currently enjoying an era that permits them to actively work and serve the society. The current status promotes women's right to education, work and participation. Existing policies also support the presence of women in all political, economic and social fields.

It is noteworthy to mention the role of the Egyptian government and its efforts over the years to elevate the status of women through a number of initiatives and interventions in all fields. For further illustration, the National Council of Women (NCW) was established to propose and legislate policies and mechanisms that would enable and empower women.

Moreover, a significant amount of work was done to combat all types of violence against women; in addition to executing a number of measures aiming to alter false community perceptions and values that impact the role of women regionally and internationally. The Egyptian constitution of 2014 has put a huge emphasis on the values of justice and equality. The constitution has over 20 articles guaranteeing women rights in all aspects. Similarly, Egypt has launched a national strategy for empowering Egyptian women by 2030, in accordance with the Global United Nations Sustainable Development Goals (UN-SDGs). These initiatives have in fact reflected the state's stance in regards to the role of women in leading a vital role in the development and advancement of the nation. 


\section{Research Problem and Question}

Egypt has witnessed a significant progress in supporting and empowering women, specifically in achieving gender equality. Additionally, Egypt has assembled its efforts to provide women with their actual position in the society, improving their situation, and eliminating any source of discrimination against them. This has reflected in a positive improvement on multiple levels; such as: increasing the percentage of women in decision-making positions and occupying leadership positions in all occupational scopes. However, some challenges remain persistent that hinder women from achieving their full potential and sustaining the economy through their enrollment in leading positions.

Therefore, the research problem is a trial to answer the key research question: How is empowerment reflected on the leadership of women in decision-making positions? Stemming from this key controversial question, a few questions arise:

1. What is the definition of empowering leadership?

2. What are the key indicators of empowering leadership of Egyptian women in decision-making positions?

3. What are the methodologies used fostering empowering leadership of Egyptian women in decisionmaking positions?

4. What are the challenges that limit the chances of women in taking over leadership positions?

\section{Research Methodology}

This research uses a descriptive approach that provides a qualitative detailed and characterized description of a certain phenomenon, and a quantitative description using figures and numbers that show the situation of the phenomenon and its relation with other phenomena in the community. This takes place through data collection, analysis and interpretation; along with coming up with concrete and solid conclusions.

Therefore, this approach can be used to define the theoretical framework of empowering leadership for women. Furthermore, the methodology provides a scope for monitoring the current situation through collecting data and expressing its significance through percentages, numerical and statistical indicators. Data shall also be closely analyzed in order for the data to expose the actual obstacles affecting the empowerment of Egyptian women.

\section{Literature Review}

A significant amount of literature have been made in light of the empowerment of women in leading positions; it is of vital importance to mention that these literature were both Arab and Western in nature. The below sections shall be divided upon these two key axes whereby the first part will examine and analyze the Arabic researches; whereas, the second part shall explore and assess foreign research in the field.

Shehata (2020) was highly concerned to identify and define the current status of women in the Arab region, with a focus on the Egyptian society. His work has gone to include the empowering leadership in social, economic and political aspects. The results of his work have showed that women have been highly empowered mostly in the social aspect; whereas the economic and political arenas still require massive improvements. The study also revealed the mutual relationship between social, economic and political empowerment, highlighting that culture is a key challenge hindering empowerment. On another note, Raslan (2017) has paid attention to the factors affecting women and deterring their inclusion in leading positions in public organizations. Raslan has agreed with Shehata that development is still needed for tangible progress to take place. In his argument, Raslan claims that there is obvious inequality in taking over leadership positions between men and women and a major factor is the structural issues that greatly affect women taking over the leadership positions. Raslan also referred to a few personal, environmental and social factors that contribute to this limitation.

Moreover, Rahoma (2017) has presented a suggested strategy for the educational role of the civil society associations to empower women. One of the main conclusions of the research was the diverse dimensions of women empowerment shown, which included the regressive ranking of economic, social, educational, and health empowerment. According to Rawshda (2016) has focused on the case of Jordanian women were she pointed out that women are limited from active participation in the political sphere. In the author's argument, this limitation has been a consequence to several restrictions in the social, political, legal, economic and media spheres.

Furthermore, Abdel Hamid (2007) has defined the reality and challenges facing the educational, technological, economic, social and health empowerment of women in regards to the Millennium Development Goals (MDGs).

In addition, the study highlighted the governmental efforts to include women and enable them. This has resulted in multiple political legislations of the Egyptian community supporting the right of women to work in the political field. However, the situation of women is limiting in nature due to the high illiteracy rates present among vulnerable and marginalized segment of women across Egypt; hence, participation remains low.

As previously mentioned, literature is divided into Western and non-Western works, having identified and 
tackled the efforts done by Arab scholars, it is important to turn to Western work in tackling the issue at stake.

Melese (2019) analyze the challenges faced by Ethiopian women as they seek to compete on decisionmaking positions. In light of these challenges, a number of outcomes were drawn; the most significant of which was directly related to women's illiteracy. A number of consequence follows this such as the lack of experience and burden of household duties. Whereas, few opportunities were prearranged in the shape of providing training and development programs to empower and enable women. On the other hand, Ioannidou (2019) has looked into the condition of women from an academic anthropological view whereby he concluded that whenever cultural and structural challenges are present, an inequality dilemma in terms of women's rights is present. This ultimately affects the academic and administrative development in the field.

Besides, Bayeh (2016) pointed that the empowerment of women in reference to the Global United Nations Sustainable Development Goals (UN-SDGs), specifically in Ethiopia, has been minimal. Also, the enrollment of women in the workforce is limited due to the monopolization of men to all high ranking positions. Women rights are highly violated in the political sphere due to the patriarchal nature of the country. Women also are directly affected by environmental factors. The researcher also concluded that if women empowerment was not achieved, Ethiopia won't be able to achieve sustainable development. Alternatively, Denisia (2016) bases his study on South Africa whereby he suggests that women are misrepresented in leading positions and are commonly faced by numerous difficulties as they seek to apply to these occupations. Nonetheless, he argues that women have proved to be more productive and efficient than men. Similar to Melese (2019), Denisia emphasizes on the impact of empowerment programs on the progression of women.

\section{Conceptual and Theoretical Framework:}

\section{Empowering Leadership of Women}

The concept of empowerment was introduced as one of the contemporary administrative concepts that sheds the light on human resources in organizations, through giving power, authority, and freedom to deal with subordinates, endorsing their human power. It is also one of the core concepts of gender related studies. As for the notion of women empowerment in specific, it has been defined by World Bank as the factors that work to nurture and foster women participation, enhance their awareness and knowledge, and so helps them achieve their goals in several aspects financially, psychologically, socially, and politically. In this way, women are enabled to control the surrounding circumstances and situation and to freely contribute to develop and build the community.

The notion of women empowerment is typically common in the field of Women Studies and international and local developmental agencies following its adoption by the United Nations through the last quarter of the past century. The UN has clearly set measurable indicators for women empowerment; these have included the percentage of women joining the workforce, and specifically holding leadership positions; the presence of new opportunities of education and training for women; the participation of women in policy and decision making processes.

According to Gleta (2017), women empowerment entails a participatory process that promotes women and community participation in improving and developing the social, economic, and political life of the community. Additionally, two key factors come to explain the concept of women empowerment: the elimination of factors that reduce women chances to reach decision-making positions and the accessibility and adoption of policies in support of women's participation.

On the other hand, John Friedman has defined women empowerment as the concept that evolves as a result of the interaction of the political, economic, and social spheres together. Friedman sees a clear relationship between empowerment and authority. Nonetheless, political authority has a broad impact through team work, the social authority originates from dealing with information and community skills; in addition to the role of the psychological power in the concept of empowerment as an individual feeling of power that appears in behavior in the form of self-respect, and confidence, so we can say that empowerment is a social power that can be translated as a political one.

Similar to Friedman's argument, Kahtany (2016) argues that empowerment is a doorway to achieve sustainable development for women. It provides all the tools that guarantee women's involvement in the community and support raising the awareness among men and women about gender equality, relationships in the family and community, helping transform the current situation.

This approach, typically, provides power to women, which accordingly means the increase of the chance of expressing themselves, the power to choose the effective social directions and to respect women as valuable citizens contributing to the development of the state. In this sense, it is noteworthy to highlight that gender equality and women empowerment come together hand in hand, complementing and building on their goals and principles. Therefore, inequality highly hinders empowerment and progression.

\section{Exploring Women Empowerment Dimensions and Aspects}

Scholars have had various opinions about determining the aspects of Women Empowerment. The majority, however, agreed about four key aspects: psychological, cognitive, economic, and political aspects. Nevertheless, 
this is not always the case due to technological, social, cultural, educational, and medical dimensions that have to be considered throughout the process. There are several economic theories that relate the concept of empowerment to the gender gap, with regards to women's participation in the workforce and their economic empowerment (Mohamed, 2015).

Additionally, women empowerment can be elaborated through a number of dimensions to foster a solid understanding and overview of actual empowerment mechanisms. According to Atta (2019), first, economic empowerment works to open the door to women controlling the resources of the family and their income; in addition to many other economic aspects as reaching to the market, finding equal job opportunities with regards to the opposite gender, reaching to high economic positions, participating in the decision-making process, endorsing the financial independence as a part of the workforce. Second, political empowerment bestows to women the right to vote and openly practice participation tools; and accordingly represent the government locally and internationally. Third, the socio-cultural empowerment provides women with the opportunity to participate beyond the borders assigned to her by family and relatives, providing a wide range of educational choices that eliminate illiteracy, and this improves women's image, role, and accomplishments. Fourth, women are to be legally empowered through capacitating them with the necessary knowledge of their right and responsibilities, allowing them to mobilize the support of the community to practice those rights. The process also seeks to pass laws that support women rights and ensure that the judicial system is ready to correct any violation that has happened in the past. Fifth, women are commonly in need to be empowered psychologically to achieve comfort and peace of mind; a key aspect of this dimension is to raise the awareness of women against oppression and acknowledge their worth and value in the community (Atta, 2019).

In Sheoran's (2016) argument, the process of empowerment entails that women have an understanding of their rights and roles; in addition to having the right to accessing equal resources and opportunities. It is highly important to shed the light that the process of women empowerment requires the active and direct input of women to tailor their own rights and solidify their status as vigorous members in the society.

\section{Exploring the Concept of Leadership}

The notion of leadership has been a buzzword; however, they came to mean different things to different people across time. In modern dictionaries of managerial terms, leadership can be defined as "The ability to influence the human behavior to direct people towards a common goal that serves to gain their obedience and trust." Another definition defines it as "The Process of stimulating joint efforts through positive interaction among individuals so that these efforts can be pursued to achieve the goals." (Badawi, 1994).

Having touched upon few definitions to the concept, Othman (1007) claims that leadership is usually perplexed with other concepts like management and presidency. Leadership differs than presidency regarding the source of the authority and the work approach. On one hand, leadership is characterized by the ability to greatly influence the subordinates rather than the authority given to the presidency to practice over them. Also, leadership is different than management that depends on doing the administrative jobs, while leadership renews and develops, depending on mutual trust and team work quintessence.

The leadership role is a behavioral activity that aims to positively affect the subordinates' behaviors and encourage them to achieve the structural goals, while the managerial role is more of a mental activity that seeks setting a clear vision and mission of the organization and its programs. Leadership, according to Abou El-Fadl (2008), derives its importance as the core of the managerial process and it contributes to achieve the needed progress and development. Therefore, organizations need leaders to run and organize their work. A leader must own several characteristics to ensure efficiency such as: being visionary, has a purpose to deliver, acquires a high degree of resilience has a high level of integrity and trust, courageous and initiative taker.

Many studies and researches have been conducted with the aim of identifying the characteristics of a women leader, her leadership styles. However, the results have shown that there are no differences between men and women when it comes to leadership styles, according to a study conducted by Ibtihag Ahmed El Aley "Women and the Managerial Leadership Styles" in 2009.

Ghoneim (2020) argues that women leadership skills are explored as a strategic indicator of women's capability to hold positions of power. For instance, a leader should balance between being both: people and task oriented. Also, women in leading positions have to own a high degree of intellectual, technical skills and competencies that aid women to get the job done efficiently and competently.

Similar to men, a woman leader is characterized by self-control, effective communication ability to influence and inspire others, time management, innovation and creativity and conflict resolution. She must be aware of her citizenship rights and duties, as well as those of other women too (Ahmed, 2009).

\section{The Case of Egypt:}

I. Indicators of Empowering Leadership in Decision-Making Positions within the period of 20142020

It can be argued that the fact that women are taking part and contributing to the public and political spheres is an 
evidence that development and scientific progress is established and sustained. This argument is established upon the basis that equating the capabilities of women with the skills of men is a significant indicator towards socio-economic development. Substantial international efforts have marked the realization of equality through the execution of a number of agreements and conventions on legal, social and political rights of women. In light of this, Egypt has achieved momentous advancement in terms of granting women their bestowed rights of education, occupation, legislation and health.

\section{Empowerment Indicators in Executive Authority}

With the rise of the first lady Dr. Hekmet Abo Zeid to the position of the Minister of Social Affairs, it paved the way forward to the genuine probability that women could high rank government positions. Following this remarkable event, Dr. Aisha' Rateb held the office of Social Solidarity in 1974 followed by Dr. Amal Othman in the same position.

The era of President Mubarak has also witnessed the rise of many female figures to power; such as: Dr. Venice Kamal Gouda, Minister of State for Scientific Research; Dr. Nawal Abdel Meneim, Minister of Economics and International Cooperation; Dr. Mervat El Telawy, Minister of Insurance and Social Affairs; Dr. Fayza Abou El-Naga, Minister of International Cooperation; Dr. Nadia Makram, Minister of Environmental Affairs; Dr. Amina Hamza Mahmoud, Minister of Insurance and Social Affairs; Aisha Abdel-Hadi held the position of Minister of Manpower and Immigration; Mushira Khattab, Minister of State for Family and Population, and Samiha Fawzi Ibrahim as the Minister of Trade and Industry (Reyad, n.d.).

Moreover, since the rise of President Sisi to power, a number of significant achievement were realized. The year 2017 has marked the accession of four ladies to Ministerial positions; and six other female figures have attained power following the 2018 announcement of the new Ministerial formation. The ministries included the Ministry of Planning headed by Hala Al-Saeed, the Ministry of Immigration headed by Nabila Makram, the Ministry of Solidarity headed by Ghada Wali, the Ministry of Investment and International Cooperation headed by Sahar Nasr, the Ministry of Culture headed by Enas Abdel Dayem, and the Ministry of Tourism headed by Rania Al-Mashat; making six Ministries headed by female figures out of thirty three Ministries.

According to Wahby (2005), under the government of Mostafa Madbouly, eight female Ministers were appointed, such as: Dr. Nevin Gamea, Minister of Industry; Dr. Enas Abdel Dayem, Minister of Culture; Dr. Rania Al-Mashat, Minister of Tourism; Dr. Nevin Al-Kabbaj, Minister of Social Solidarity; Dr. Yasmine Fouad, Minister of Environment; Dr. Hala Al-Saeed, Minister of Planning and Economic Development; former Ambassador Nabila Makram, Minister of Immigration; Dr. Hala Zayed, Minister of Health and Population; Ghada Nabil, Deputy Minister of Communications and Ghada Shalaby, Deputy Minister of Tourism and Antiquities. In addition, it has been the first time where a female figure is appointed as the assistant of the Prime Minister: Dr. Randa El-Menshawy.

\section{Empowerment Indicators in the Judicial Authority}

According to Wahby (2005), since the 1940s, women have pursued judiciary positions. A remarkable historical evidence of this was the court case raised by her Excellency, Aisha Rateb, serving as the Minister of Social Affairs, against the Ministry of Justice due to her rejection in the Council of State despite the fact that she meets the required qualifications.

Although many females have been working in the legal affairs since the 1930s, there has never been a woman serving as a judge up until 2003. Her Excellency Mrs. Tahany El-Gebaly was appointed as the first Egyptian judge in the constitutional court in 2003. Following this noteworthy step, thirty-one other ladies were selected to hold judiciary power in the years 2007 and 2008. Besides, twenty-six ladies were appointed as judges in 2015 raising the bar to sixty-six women out of a total of sixteen-thousand judges all over Egypt. Another noteworthy achievement was the appointment of Chancellor, Mrs. Faryal Hamida Qutb, as President for the Administrative Prosecution Authority, preceded by Counselor / Laila Jaafar.

Hereby, Beranya (2020) highlights that it has been evident that the presence of female figures is a crucial cornerstone and a main pillar for the development of the state's institutions. This can be inferred from the number of achievements reached following the accessions of female figures to high ranks positions in the judiciary body in specific, and in all political, economic and social spheres at large. Women have gone further to become heads of the Administrative Prosecution Authority and Vice-President of the Constitutional Court.

\section{Empowerment Indicators in the Legislative Authority}

Egyptian women are in fact the first to take place in the parliament before any other Arab state in the region. Women came to hold parliamentary seats in 1957 as President Nasser recognized women's right to vote and run for elections. Back at the time, eight women were the first to apply for candidacy with the first Egyptian women, Mrs. Rawya Attia to hold a parliamentary seat. According to official governmental sources published in 2015, women constituted 15 percent of the aggregate Parliament members whereby 89 women held parliamentary seats with 75 ran for free and direct suffrage, whether through competition for individual seats, or by absolute list.

The Egyptian center for Strategic Studies highlights that the constitutional reformation of 2019 has worked on adjusting the article number 102 which has raised the parliamentary gender quota of women to 25 percent, 
which was later achieved in year 2020 as women took over 148 seats for the first time in history. That is in addition to 20 ladies being appointed by the President in the Egyptian Senate, even taking over a position of the Deputy of the President of the Senate (Beranya, 2020).

\section{Empowerment Indicators in Municipalities}

The year 2017 marked the Egyptian Women's year as the first female governor, Mrs. Nadia Abdou, was appointed to be the governor of El-Beheira governorate. In addition to the appointment of 4 female deputy governors, where women occupied a significant quota in the position of deputy governors reaching $31 \%$ in 2019 , as well as subjugating 24 percent of the local administration leadership in the governorates. Therefore, in reference to El-Masrawy news, the percentage of women holding leadership positions in local administration positions has increased from 7 percent to 16 percent in its totality in 2019.

Besides, three women have gone further to hold higher posts as assistant general secretaries in Qena, Gharbia and Dakahlia governorates instead of solely being heads of neighborhood councils. Furthermore, sixteen women came to be formally recognized as head of municipalities and cities. It is important to note that women quota has reached 2 percent in local municipalities and councils, according to 2014 constitution.

\section{Empowerment Indicators in the Public Sector}

The Ministry of Planning has issued a report in 2020 emphasizing that the percentage of working women in the public sector has increased to 45 percent in comparison to the aggregate number on an international level that is commonly within the range of 32 percent. In addition, the participation of women in managerial positions has been raised from 9.7 percent in year 2017 to 10.2 percent in year 2018. Women were also able to take part in the board of directors in the banking sector with a percentage of 12 percent in 2019 in comparison to 10 percent in 2018. The percentage of women executive leaders reached 1.7 percent, which is higher than the average in the Middle East and North Africa, that is estimated at 4.5 percent; whereas, the percentage of female editors-in-chief of national newspapers constituted an average of 18 percent. This increase has indeed been a significant indicator of development in terms of women's active participation in the public dimension.

It can be inferred from the aforementioned data that the indicators of empowering leadership for women has been clearly noticeable over the period of 2014-2020 through the below mentioned percentages.

The percentage of women ministers in the Council of Ministers increased from 6 percent in 2015 to 20 percent in 2017 and then to $25 \%$ in 2018, which is the highest ever degree of representation of women in the Egyptian Council of Ministers. Egypt has also witnessed an increase in the percentage of women occupying the position of deputy minister from 17 percent in 2017 to 27 percent in 2018 . As for the percentage of women in the post of deputy governor increased to reach 31 percent in 2019. Besides, women have come to occupy 2 percent of the parliamentary seats in 2013 to 15 percent in 2018 and 25 percent following the constitutional amendments of 2019.

The increase in the proportion of women on boards of directors in the Egyptian Stock Exchange to reach 1.10 percent. As for the banking sector, women were represented with over 8.14 percent. On the other hand, the public sector marked 6.1 percent; and the Financial Regulatory Authority has seen a transformation reaching to 11 percent; while, the percentage of women leaders at executive positions extended to 7.1 percent.

Likewise, for the first time, an Egyptian woman, Dr. Ghada Wali, reached the position of Deputy-SecretaryGeneral of the United Nations and Director of the Executive Office of the United Nations Crime Office and Director of the International Organization's Headquarters in Vienna, after assuming the position of Minister of Social Solidarity. Similarly, Counselor Amal Ammar reached the position of representative of the Republic of Egypt after the elections that took place at the African Union headquarters in the Ethiopian capital Addis Ababa, representing the northern region. Women also reached the position of the first deputy governor of the Central Bank with Lubna Hilal assuming the position.

The Global Report on the Gender Gap 2020 also indicated the progress of the Egyptian state in the Women's Political Empowerment Index, as Egypt ranked 103 out of 105.

\section{Empowering Egyptian women in decision-making positions between mechanisms and challenges}

Part one: Mechanisms for empowering Egyptian women in decision-making positions in the period from 2014-20

The Egyptian government has taken several measures and adopted many legislations that support women, especially in the period from 2014-2020, illustrated as follows:

\section{a. Women in the Constitution of 2014:}

The study by Ezz El Din et al (2020) claims that this constitution is considered one of the greatest documents that supported women rights throughout the Egyptian history, where it supported the elimination of gender-based discrimination in several fields, allowing equality to prevail and be a real accomplishment.

Article no.11 in the constitution stated that the State guarantees gender equality with respect to all civil, economic, political, social, and cultural rights and also applies all the policies and procedures to guarantee women fair representation in the parliament according to what the law states. Likewise, in order to ensure that women have fair opportunities in taking over governmental and leadership positions in all the authorities and the 
judicial authority without any sort of discrimination and protecting women against all sorts of violence, empowering them to balance between career and family (Gamil et al, 2020).

The State also applies the needed procedures to guarantee fair representation of women in the parliament abiding by what the law states, as in the article 180 of the constitution it is stated that 25 percent of the parliament members should be women, which is 13,500 of the total number of members. Article no. 6 allows the Egyptian woman to pass the Egyptian nationality to her children. While article 214 provides the political independence of the National Council of Women giving it the right to review all women related legislations before they are announced (Kazem, 1993).

Correspondingly, Article 17 guarantees providing the needed social services for women. Article 19 necessities that all women should enroll in the educational system till at least the secondary level; this was an unprecedented step towards facing the issue of early marriage. Articles 93 pronounces the importance of abiding by international conventions and charters of human rights that Egypt has ratified.

\section{b. Women in Labor Law}

The state has actively adopted the notion of social solidarity and equal opportunities as it has granted women the same labor rights and responsibilities granted to men. According to Kazem (1993), labor legislation also granted many advantages that facilitate women to carry out their duties as heads of families responsible for raising a new generation and working at the same time.

The period from 2014 to 2020 witnessed several legislations supporting women's rights in general, such as: first, Amending the law regulating the Family Insurance Fund (Law No. 113 of 2015) to increase its resources to meet the needs of women, Amending the Penal Code (2016) in Article 242 (regarding female circumcision, where the crime was raised from a misdemeanor to a felony. Second, the new investment law (Article 2) guarantees equal investment opportunities for both men and women, as well as the Egyptian tax law recognizes woman as the breadwinner for the family under the unified tax law. Third, the law regulating the work of the National Women's Council (Law No. 30 of 2018) was issued to promote the speaker of the council to the position of minister and to acknowledge a broader political role with regard to women's empowerment. This is besides amending the 2016 Civil Service Law for four months instead of three, which grants benefits to working mothers such as the maternity leave. In addition to other advantages as the issuance of the social security and pension's law of 2019; as well as, the issuance of the decree of the financial supervisory authority for the year 2019, which stipulated the representation of at least one woman on the boards of directors' financial companies. Moreover, the President Sisi has made a noteworthy announcement in 2017 declaring it the Egyptian Women's year. A new Law No. 30 of 2018 was also issued regarding the National Councils, which authorized that 2017 was the year of its independence from the executive authority contributing to greater degree of independence to the National Council for Women, chiefly in regards to issuing its decisions and selecting its members, as well as expanding its competencies.

\section{c. Women Empowerment Strategy of 2030}

Egypt has been amongst the very earliest countries to issue a national strategy focused on empowering and enabling women that is in accordance with Global Sustainable Development Goals. This initiative has clearly reflected Egypt's vision in the fundamental role of women in development. President Abdel Fattah El Sisi has approved the National Strategy for the Empowerment of Egyptian Women 2030 in 2017, which is a road map for the Egyptian government to implement all programs and activities related to empowering women, the strategy contains 34 indicators of sustainable development goals.

The vision of the Strategy for Empowering Women 2030 is based on the fact that by 2030, Egyptian women will become a major player in achieving sustainable development in a country that guarantees them all their rights secured by the constitution; and achieves full protection for them and fully combat any sort of discrimination the economic, social and political opportunities that enable them to advance their capabilities. By extension, its role in upholding the nation, and achieving the vision and objectives of the National Strategy for the Empowerment of Egyptian Women 2030 requires working through four axes, which are "Political Empowerment and enhancing leadership roles for women, Economic empowerment, Social empowerment and protection.

In the axis of political empowerment and strengthening women's leadership roles, it is inferred that the percentage of females were able to occupy five percent out of the 17 percent that is desired to be reached by 2030. The strategy identified a number of indicators to measure the impact of the axis of political empowerment, among which the percentage of females out of the total electoral participants is 44 percent currently; whereas, the strategy aims to reach 50 percent by 2030 .

The strategy defined certain initiatives that aim to promote the role of women in elections through providing all women in Egypt with their national ID cards, raising the percentage of women presence in the parliament, enhancing women performance through training about key occupations, providing the current female parliament members with all information and experience needed to make their role more effective.

Also increasing the percentage of women working in judicial authorities and raising their level of 
performance, the strategy added certain steps to promote the role of women to take over leadership positions in the judicial authorities, identifying a clear criterion to choose the candidates for these positions and eliminating gender discrimination, setting the quality and competency as a priority. Also, the same applies for giving women opportunities to work in the public sector, ministries, local authorities, and the private sector. (NCW report, 2018)

The National Council of Women has defined key tools to follow up and evaluate those strategies along with a solid monitoring and evaluation plan. Additionally, there would be electronic instruments in place that is inclusive of advanced statistical and technological tools to measure inputs and outputs. (NCW, 2017)

\section{d. The Egyptian government's efforts in women's empowerment internationally}

Egypt has had a concrete presence on an international level with a focus on its impact in the field of women empowerment. Egypt has developed multiple cooperative agreements with both neighboring and distant countries. Having said that, Egypt participated in the 57th session of the United Nations Commission on the Status of Women from 4 March to March 17, 2013 to reach consensus on the International Document to End Violence against Women and Girls; it also participated in the 58th session of the Committee on the Status of Women from 10 to 24 March 2014 under the title "Application of the development goals for women and child". The conditions that Egypt has faced in order to achieve the Millennium Goals were thoroughly reviewed. Therefore, the delegation of Egypt stressed on the importance of setting an international agenda for the post2015 period that ensures continued focus on development issues; as well as the continued existence of the goal of empowering women and achieving gender equality.

Furthermore, Egypt has taken an active part in formulating the strategy of the Arab regional to execute and implement the policy of Security Council number 1325 within the framework of the Arab League. According to Al-Bawaba News, the strategy adds a huge emphasis on ending violence against Palestinian women in the Palestinian land and strengthen the role of women in combating terrorism. It is worth highlighting that Egypt has publicly stated last May of 2019 the initial national work plan and the implementation of the agenda related to women, peace and security. Additionally, the United Nations of Women - Egypt is highly concerned with empowerment of women and ensuring that equality mechanisms is in place. UN Women Egypt is in a solid partnership with the Government of Egypt and the National Council of Women and the Ministry of Social Solidarity and civil society organizations with the aim of formulating a comprehensive agenda that builds on the existing interventions to promote and multiply the efforts done by all relevant stakeholders; and hence ensure a comprehensive development and social justice.

\section{Part two: Challenges of Women Empowerment in Decision-Making Positions}

Through a thorough review of a number of studies and researches, it can be inferred that a number of challenges face women in leading positions, these include:

\section{A. Social and Cultural Challenges}

These originate from the prevailing customs and traditions of the community, the level of education and how the nation was raised. Traditions play a chief role in forming the gender identity and strengthening the gender differences; therefore, we cannot study or analyze women's status without referring to the community they reside. (Wahby, ibid)

In Nasser's (2009) opinion, the prevailing mindset and cultural traditions and practices is discriminatory in nature. For instance, enrolling in the job market is not of the same importance for women as it is for men due to the social and economic responsibilities entitled to each gender. Al Sen (2012) points out to the customs and traditions also contribute to discrimination against women when it comes to reaching decision-making and leadership positions, where the male dominant culture prevails and monopolizes public positions. Such patriarchal culture affects women's behavior and the opportunities they have to enhance their skills; which by extension affects their political and social performance. This male-dominated society commonly influence the political ideologies women adopt; besides their social construct. This is primarily due to the fact that this creates a traditional frame where women are expected to perform household duties without further engagements in the community. (Abo EL Komsan, 2014)

In addition to the prevalence of stereotypes and prejudices based on cultural norms, the World Bank (2018) suggests that the most prominent stereotypes and prejudices in various sectors are related to the suitability of women for certain jobs, as some view women as competent in skills related to communication, detail-oriented, work ethics and multitasking. On the other hand, a prevailing perception about men rests upon the assumption that they are skilled at working under extreme stress, as they separate their emotions from their work, and have greater physical strength and have unconscious biases. These stereotypes have created a biased view about the occupations women can hold and that several positions do not suit the feminine identity; and therefore, women are not fitting and less capable and qualified than the male segments.

\section{B. Political and Legal Challenges}

El-Rawsha (n.d.) claims that these challenges are represented in the lack of awareness of women's legal rights, whether in the media or in educational institutions, and the lack of so-called means or tools for political and legal 
education at the level of civil society bodies, especially political parties, trade and professional unions, and women's organizations. In addition to the lack of knowledge Women have their legal and political rights represented in the possibility of their participation in political work, as they have not worked to empower themselves politically and have not acquired sufficient experience necessary to qualify them to run for elections with a strong will and conscious of their rights and duties.

The political participation of women is characterized by fragility due to Boderham's (2019) assumption that many women are reluctant to participate in political life in Arab societies; and this is what made their role in the political field weak and low in all decision-making positions.

There are also obstacles related to the legislation. In other words, some laws do not support the right of women to be promoted to leadership positions, especially positions in which appointment is limited to the principle of selection, which actually translates into withholding these positions from women and restricting them to male candidates. Additionally, there is a significant lack of sufficient laws and legislations to help women balance the traditional, costly roles in caring for their household responsibilities besides their day to day work. Consequently, the lack of the necessary amount of qualified communal understanding that enables women to participate in the activities of society, the lack of awareness of rights and duties in this field, and the absence of a female component in decision-making positions leads to the emergence of legislation that focuses on the interest of men at the expense of women. In conclusion, despite the growing role of women in public life, their role in decision-making positions is still weak (Bayoumi, 2015).

\section{Personal Challenges}

In a research conducted by Serag El Din in 2008, he stated that Women personal Challenges are related to skills, roles and competencies. Her negative self-image has resulted in her decision to step back from participating in the public life, which paved the way to the current difficulty that is to convince women to change their view.

The feeling of inferiority that is rooted in the community resulted in the absence of the will to take over leadership positions and also the difficulty in balancing household and public duties. In the family, women have the greater role whether they work or only manage the household, this is a constraint that raises conflicts related to gender roles.

In addition, Al Tarawnah and others study in 2011 found out that another important issue is the challenge of time management in work and home, which encourages women want to retire and quit work earlier than what is stated by law. Women commonly refuse high-rank positions that require longer working hours. On the other hand, women are frequently challenged with in the fear of failure and lack of self-confidence. A high turnover rate in women is witnessed among all specialties and occupation due to several reasons, such as: marriage constraints and maternity loads. These challenges usually lead to the fact that women are less experiences and qualified, with no clear potential of a solid career path.

\section{Economic Challenges}

The main reason of low rates of women presence in the workforce is a set of interrelated factors, including the discriminating regulatory frameworks, the limited chance of getting suitable training, the high cost of some unpaid tasks as raising children, household duties, and poor working conditions. All these factors result in low wages, mostly with absence of social security and the presence of some discriminating social and cultural rules, the limited chance of resources control and acquisition (land, ownership, funds, etc.) and the lack of suitable jobs in the market.

According to a study conducted by Lebanese American University in 2019, there are other factors that affect women participation in the Economic field, due to the traditional perception that the role of man is to provide for the family; whereas, women are to take over household duties only. Moreover, the absence of a flexible work environment and/or flexible working hours adds to the economic burden of women. Economic challenges are also pertained to the absence of regulating laws on gender-based wages.

\section{E. Organizational Challenges}

Shalaby (2018) assumes that as the work climate rarely supports women's career advancement with the same level of support for men, accordingly working women suffer from the absence of a trained leader. This primarily results in the scarcity of female managers, entrepreneurs, professionals and experienced women. Working women suffer from the absence of supportive social networks and the difficulty of entering social networks existing at the level of middle and upper managements as they barely make it to these positions, in the first place. The general climate of institutions has contributed to the lack of rotation of positions of authority for a long period; in addition to the absence of a culture of training and skills development. Therefore, women's access to decision making positions was impeded due to the lack of weak training opportunities and the absence of a supportive work environment.

\section{Results and Concluding Remarks}

The research addressed the issue of women empowerment in leadership positions in the period from 2014- 2020. The paper primarily aimed to monitor the status of empowerment towards women along with the tools facilitated 
by the government and civil institutions to enable women and integrate them as active members in the society. The study has also shed the light on the various challenges that hinder the empowerment processes. The paper has also overviewed a number of eras and domains. Although an advancement is clear and governmental efforts are evident, a number of further interventions are necessary before we see the fruits and set the ground for an equal society.

It can be concluded that the notion of women's empowerment and their leadership role is one of the important issues that has received and continues to receive great attention, both at the level of research studies, as well as in conferences and scientific symposia. It also receives the attention of governments worldwide, which means that the level of awareness has increased in regards to the importance of the role of women in society and the extent of which contribution affecting development issues in general.

The results of the study also showed that the aspects of women's empowerment varied between political, social, economic and legal empowerment; all of which ultimately lead to the goal of empowering women to reach decision-making positions in a way that makes them able to fully contribute to their leadership positions.

By monitoring the most important indicators of the empowerment of Egyptian women in decision-making positions, the study showed several points. These have included the fact that women are actually able to dominate positions that have long been associated with male counterparts. By extension, this fact can highly influence the false perceptions of the society that women are solely responsible for household duties. Through the current era, Egyptian women witnessed gains and successes that they aspired for long. The study also showed that the leadership empowerment of women is progressing at a fast and advanced pace, which indicates that the empowerment of women is amongst the key goals of the 2030 vision.

By clarifying the mechanisms of empowering Egyptian women in the period from 2014-2020, the study showed the great interest that the state attaches to empowering women and elevating their role in various fields to assume the position they deserve in society, and upholding the values of equality established by the constitution, as the positive steps taken by Egypt towards approving the principle of citizenship and women's rights.

It is noticeable in the issue of empowering Egyptian women that it is linked to the orientations of the political leadership, and this means the extent of the political will's belief and awareness of the importance of empowering women in society. Issuing the national strategy for women empowerment is amongst the earliest and exceptional steps that the government has taken to ensure a solid implementation of the Global United Nations Sustainable Development Goals.

The Egyptian government has been able to take firm steps in the field of achieving equality and empowering women through several measures, such as the declaration of the Egyptian Constitution 2014, which guarantees women equal rights. Besides, the state was keen to develop a national strategy to empower women's political and legislative affairs, through the adoption of a number of new legislations and the amendment of existing laws to ensure full equality and equal opportunities for Egyptian women that support their active participation in the societal sphere without discrimination. Egypt has also adopted many legislation and programs and ratified relevant international agreements in this regard.

Nevertheless, despite all the efforts made by the Egyptian government in that period, but this does not mean that there are no challenges faced by women and that reduce the chances of them assuming leadership positions. Women still suffer from many obstacles, which are not the result of the moment, but as a result of many practices based on a group of customs and traditions.

By reviewing the most important challenges, we find that cultural and societal challenges have a significant impact on the empowerment of the Egyptian woman. The Egyptian society still inherits negative ideas about the woman and her role limited to the home, and the patriarchal culture in education is still prevalent in many families of the Egyptian people, which negatively affects the perceptions of both, men and women. Hence, although principles of equality are highlighted in theory, the applied practices remain the stumbling block in the way of women's leadership empowerment. The cultural practices and beliefs affect all aspects of women's empowerment; for example, economic challenges are the result of the traditional division of the roles of women and men and limiting their role to family and home responsibilities. We also find that poverty and illiteracy play a major role in the way women empowerment. Therefore, empowerment requires ending scarcity and augmenting literacy levels; yet, this is expected to take a long time to come to reality.

Thus, it is possible to reach the main search result, where the political leadership is the key compass and drive for the status of women. The political leadership has found support and desire from all state institutions, as well as institutions concerned with women's rights, such as the National Council for Women, as well as civil society institutions, which is clearly reflected in the numbers and statistics that indicate an increase in the percentages of Egyptian women's representation in decision making.

But there are still many challenges that women face and that reduce the chances of them taking leadership positions, whether they are personal, economic, organizational, political or cultural challenges. These challenges face women all over the world, but the percentage of impact of these challenges varies from one place to another. 
The more countries advance, the fewer these challenges. Challenges, so we find their impact, is greater in developing countries and Arab countries.

\section{Study Recommendations}

In light of the results of the study, some recommendations can be made regarding the empowerment of Egyptian women:

1. Shed the light on the achievement of women in decision-making roles and raising the awareness of women about her legal rights through media channels.

2. Altering the patriarchal perceptions of the society as well as the necessity of adopting the issue of empowering Egyptian women as a societal issue of importance in achieving development goals. The necessity of supporting the political leadership in its goals regarding the empowerment of Egyptian women through the implementation of its strategy.

3. Renewing the language of religious discourse through preachers and thinkers and highlighting the status and rights of women in Islam.

4. Providing the necessary support to women to enable them to perform their work efficiently and effectively by providing facilities that enable her to balance the demands of family and work. Also, giving women the opportunity to train and develop capabilities in all different fields of work

5. Changing the organizational culture that is biased towards men, claiming that women are unable to take over leadership positions.

\section{References}

Badawi, A. (1994). Glossary of terminology of scientific administration.

ElDin, I. (2008). Women Rights: Steps towards reformation. Alexandria: Alexandria Library.

Kazem, R. (1993). Management and Egyptian Community. Egypt: The Egyptian General Book Authority

Farag, T. (1993). Leadership Behavior and Management Effectiveness.

Ahmed, A. (2009). Women's administrative leadership, a psychological approach. Riyadh: Dar El Moeaid.

Abo El-Fadl, A. (2008). Leadership and management in contemporary Arab thought: roles and components. Riyadh: Naif Arab University for Security Sciences.

Wahby, A. (2005). Egyptian women in decision making positions. Cairo: National Council of Women.

Nassar, H. (2009). Research Program on Women and Work Policy Papers. Cairo: Social Research Center.

Adly, H. et al (2017). Women political participation. Lebanon: Fredrick Ebert Association.

Shalaby, S. (2018). Women and administrative leadership in Egyptian governmental organizations: a university case study in Zagazig, Master Thesis. Suez Canal University: Faculty of Commerce.

Raslan, M. (2017). Factors affecting women's assumption of leadership positions in Egyptian public organizations. Ph.D. thesis. Cairo University: Faculty of Economics and Political Science.

ElAli, E. (2009). Women and Administrative Leadership Styles. Journal of Commerce and Finance, Tanta University, College of Trade, Issue 2.

Shehata, A. (2020). Empowering Egyptian women: A descriptive study of the visions and trends of some female intellectuals Egyptology in Damietta Governorate. Journal of Social Sciences and Development Research, Parts I and II.

Mohamed, A. (2015). Recent trends in women's empowerment and community development. Journal of Studies Arabic for Education and Psychology, Issue 67.

Qahtani, E. (2016). Attitudes of Saudi female academics towards the issue of empowering women, Journal of the College of Service Social Studies and Social Research, Fayoum University, Issue 2.

Bayoumi, E. (2015). A proposed perception of the role of women in political life in Egypt after the revolution January 25. Journal of the Faculty of Arts, Zagazig University.

Atta. H. and Ismail, N. (2019). Determinants of Women's Empowerment in the Arab Countries. Journal of Human Sciences the Social, Volume 46(1).

Abdel-Hameed, S. (2007). Empowering Egyptian women to activate their development participation in the context of the millennium development: An educational strategy. Journal of the College of Education, Volume 2(65).

Balol, S. (2009). Political Empowerment of Arab Women between International Decisions and Trends and Reality. Journal of Damascus University for Economic and Legal Sciences, Volume 25(2).

Abdelaziz, A. (2012). The potentials and opportunities available to Arab women under legislation the current Arab organization to contribute to sustainable development. Cairo: Arab Administrative Development Organization.

Al-Rawshda, A. and Arab, A. (2016). Obstacles that limit Jordanian women's participation in political life in light of some social variables: a field study on a sample of women pioneers in the North, Journal of Human and Social Sciences Studies, Volume 3.

Boderhem, F. (2019). Political participation and political empowerment of women: obstacles and challenges and treatment mechanisms in the Arab world. Algeria, Faculty of Law and Political Science, University of Muhammad Boudiaf.

Ghoenim, F. (2020). Women's leadership excellence and its motives in the academic field in universities Saudi Arabia, The Arab Journal of Al-Darah, Volume 40(1).

Habani, K. (2012). Activating mechanisms to protect human rights in women and the international and Arab community: the work of Arab women's forums in public and political life. Cairo: Arab Administrative Development Organization.

Tarawna, N. et al (2011). The reality of administrative empowerment of women in public Jordanian universities and the obstacles affecting it from the point of view of faculty members. Mutah Journal for Research and Studies, Human and 
Social Sciences Series, Volume 26(4).

Ahmed, N. (2017). Proposed strategic features of the educational role of NGOs to empower illiterate women in Egypt Journal of the College of Education, Al-Azhar University, Part Two, Issue 17.

Gamil, N. et al (2020). Political Empowerment of Egyptian Women in the Light of Their Occupation of Senior Governmental Positions from 2005 to 2020: A Comparative Study. Journal of Politics and Economics, Suez University, Volume 6(5).

Ahmed, F. (2009). Egyptian Women in Secondary Leadership Positions, Journal of Population Research and Studies in Egypt.

World Bank (2018). Study on Women's Economic Empowerment. International Bank for Reconstruction and Development. Lebanese American University (2019). Women's Empowerment in Egypt, Policy Paper.

The National Council for Women (2018). Follow-up report on the role of ministries, universities and various agencies in implementing the national strategy for the empowerment of Egyptian women. Cairo: The National Council for Women.

ElKomsan, N. (2014). Egyptian Women's Status Report. Cairo: The Egyptian Center for woman Human Rights.

Abdallah, H. (2004). Gender and Development in the Middle East and North Africa: Women in the Public Domain. World Bank Publications.

The Arab Institute for Planning, Human Development and the Concept of Women Empowerment. Retrieved from: arab.api.org/ar/training

Riad, Y. (n.d.). The role of women in the executive authority: a comparative study between Egypt and the United States in the period (2001-2019), the Arab Democratic Center. Retrieved from: https://democraticac.de/?p=6106

Akhbar Electronic News. Retrieved from https://akhbarelyom.com/news/newdetails/2604182/1/6 https://m.akhbarelyom.com/news/newdetails/2968901

The achievements of Egyptian women in 6 years, available on the website of the State Information Service.

The Egyptian woman in the ministry is a success story, available on the SIS website.

The Egyptian Woman in Four Years, Available on the State Information Service website

Achievements of women in 6 years of Sisi's rule.

The golden age of Egyptian women: Achievements and achievements that history will not forget.

The Ministry of Planning monitors the efforts of the Egyptian state to empower women. Retrieved from https://www.youm7.com/story/2020/11/16/\%D9\%88

Baranya, A. Empowerment Efforts: Highlights of the Successes Achieved by Egyptian Women in 2020. The Center AlMasry for Thought and Strategic Studies. Retrieved from https://www.ecsstudies.com/1394

UN Women Egypt. Retrieved from: https://www.ecsstudies.com/1394

Legislation and laws that support the role of women in society. Retrieved from: https://www.sis.gov.eg/Story/206613/\%

Legislatively, politically and economically: the most prominent efforts of the state to empower Egyptian women. Retrieved from https://www.elwatannews.com/news/details/5368220

El-Masrawy El Youm, Harvest 2017, Egyptian women are the title of the future. Retrieved from: http://www.almasryalyoum.com/news/details/1237612

Women empowerment strategy of 2030. Retrieved from: https://www.sis.gov.eg/PDF/Ar/1/115.pdf

Modern Egypt: Learn about the efforts to empower women during the era of Sisi. Retrieved from: https://www.albawabhnews.com4235708

National Council of Women. Retrieved from: https://www.albawabhnews.com4235708

United Nations, Women's Economic Empowerment. Retrieved from: https://arabstates.unwomen.org/ar/what-wedo/economic-empowerment.

Ngcobo, A. (2016). Analyzing the Empowerment of Women Leadership: A Case of the Durban university of Technology, Master, Faculty of Accounting and Informatics, the Durban University of Technology.

Rahman, A. (2013). Women's Empowerment: Concept and Beyond, Global Journal of Human Social Science , Issue 6, Folder 13.

Bayeh, E. (2016). The role of empowering women and achieving gender equality to the sustainable development of Ethiopia, Pacific Science Review B: Humanities and Social Sciences, Volume 2, Issue 1.

Gleta,E.; Henry, B.; Cwrol, B. (2017): The Challenges of Empowering Women: the Experience of pulse, ovation project in Southern Ethiopia.

Ioannidou, E., Letra, A., Shaddox, L., Teles, F., Ajiboye, S., Ryan, M., D’Souza, R. (2019), Empowering women researchers in the new century: IADR's strategic direction. Advances in dental research, 30(3).

Jaideep, S. (2016), Aspects of Women Empowerment:A Brief rev, International Research journal Management Science \& Technology, Issue 4, Folder 7.

Mishra, G. (2016). The Psychological Facets of Women Empowerment at Workplace, International Journal of Recent Trends in Engineering Research, Volume 2 (11).

Nigist, M. (2019. Challenges and Opportunities of Women Empowerment in Leadership Position in Ethiopia, European Journal of Business and Management, Volume 11(13) 